\title{
PENGARUH ISLAMIC PROGRESSIVE MUSCLE RELAXATION (IPMR) TERHADAP PENURUNAN KADAR KORTISOL PASIEN PRE OPERASI DI RUANG AZZAHRA 2 RSI JEMURSARI SURABAYA
}

\author{
Chilyatiz Zahroh*, Khamida*, Nanang Rokhman Saleh** \\ *Fakultas Keperawatan dan Kebidanan Unusa \\ *Fakultas Ilmu Keguruan dan Ilmu Pendidikan \\ Univeristas Nahdlatul Ulama Surabaya \\ Email: chilyatiz@unusa.ac.id
}

\begin{abstract}
Surgery is a medical action can cause stress on the patient. Stress patient who will undergo surgery must be well managed in order not to harm patients. The purpose of this study was to analyze the influence of Islamic progressive muscle relaxation (IPMR) against the patient's decrease cortisol levels.

This research was experimental research with approach of pre-post test design. The population were all patients treated in Azzahra during September 2017, with research samples of 30 respondents obtained via simple random sampling techniques. Independent variables was Islamic progressive muscle relaxation, whereas cortisol levels was dependent variables. The data of Cortisol levels was collected through the patient's blood sample. Data were analyzed with a Wilcoxon signed rank test.

Results of the study indicate that there are significant levels of cortisol after patient's IPMR. Cortisol levels in the normal range can modulate the immune system so as to strengthen the body's immune. Nurses can make the effort an effective, easy and cheap to reduce stress to patients who will undergo surgery with technique IPMR.
\end{abstract}

Keywords: Islamic, Progressive, Muscle, Relaxation, Cortisol, Stress

\section{ABSTRAK}

Operasi atau tindakan pembedahan merupakan tindakan medis yang dapat menyebabkan stress pada pasien. Stress pasien yang akan menjalani operasi harus dikelola dengan baik agar tidak merugikan pasien. Tujuan penelitian ini adalah menganalisis pengaruh Islamic progressive muscle relaxation (IPMR) terhadap penurunan kadar kortisol pasien. Penelitian ini adalah penelitian eksperimental dengan pendekatan pre-post tes design. Populasi target adalah seluruh pasien yang dirawat di Ruang Azzahra 2 selama bulan September 2017, dengan sampel penelitian sebesar 30 responden didapatkan melalui tehnik simple random sampling. Variabel bebas adalah Islamic progressive muscle relaxation, sedangkan variabel tergantung adalah kadar kortisol. Pengumpulan data kadar kortisol melalui sampel darah pasien. Data dianalisis dengan Wilcoxon sign rank test.

Hasil penelitian menunjukan bahwa ada pengaruh yang signifikan kadar kortisol pasien yang dilakukan IPMR. Penurunan kadar kortisol dalam batas normal dapat memodulasi sistem imun sehingga memperkuat kekebalan tubuh. Perawat dapat melakukan upaya 
yang efektif, mudah dan murah untuk mengurangi stress pasien yang akan menjalani operasi dengan tehnik IPMR.

Kata Kunci: IPMR, Kortisol, Pre Operasi

\section{PENDAHULUAN}

Operasi atau tindakan pembedahan merupakan tindakan medis yang dapat menyebabkan seseorang menjadi stress, karena tindakan medis tersebut dapat menyebabkan ancaman terhadap tubuh, integritas dan jiwa seseorang. Derajat stres pada pasien pre operasi sangat tergantung pada kesiapan psikologi. Sebagian orang terkadang tidak mampu mengontrol stress yang dihadapi, sehingga terjadi disharmoni dalam tubuh (Zahroh, 2017).

Stres yang berlebihan dapat membahayakan kondisi pasien saat operasi, karena dapat meningkatkan kerja sistem kardiovaskuler sehingga tidak mampu mengalirkan darah ke seluruh tubuh dengan jumlah adekuat. Hal tersebut mengakibatkan gangguan perfusi organ vital, seperti jantung dan otak. Sementara tindakan operasi mensyaratkan pasien harus dalam kondisi tenang agar dapat berjalan sesuai dengan jadwal. Kenaikan tanda vital ini yang menjadi alasan dokter dengan terpaksa menunda jadwal operasi. Intervensi keperawatan sangat diperlukan dalam mempersiapakan pasien pre operasi baik secara fisik maupun psikologis (Zahroh, 2017).

Tindakan keperawatan yang dapat dilakukan untuk mengurangi stress pada pasien pre operasi adalah terapi Islamic progressive muscle relaxation (IPMR). $I P M R$ ini merupakan teknik relaksasi yang menggabungkan antara dzikir dengan Progressive muscle relaxtion atau relaksasi otot progresif. Dzikir adalah suatu perbuatan mengingat, menyebut, mengerti, menjaga dalam bentuk ucapan lisan, gerakan lisan, gerakan hati atau gerakan anggota badan yang mengandung arti pujian, rasa syukur dan doa dengan cara-cara yang diajarkan oleh Allah dan Rosul-Nya, agar hati dan pikiran lebih tenang, nyaman dan rileks serta memberikan perasaan dekat dengan Tuhan. Relaksasi otot progresif merupakan kegiatan untuk mengendurkan ketegangan jasmani yang nantinya akan berdampak pada penurunan ketegangan jiwa (Lestari \& Yuswiyanti, 2015).

Data Studi pendahuluan pada pasien pre operasi di Ruang Azzahra RSI Jemursari, pada bulan Agustus 2017 adalah 1 orang pasien gagal operasi karena cemas berat.

IPMR mempunyai efek sensasi menenangkan anggota tubuh, perubahan- perubahan yang terjadi selama maupun setelah relaksasi mempengaruhi kerja saraf otonom. Respon emosi dan efek menenangkan yang ditimbulkan oleh relaksasi mengubah fisiologis dominan simpatis menjadi dominan system parasimpatis. Dalam keadaan ini, hipersekresi katekolamin dan kortisol diturunkan dan meningkatkan hormone parasimpatis serta neurotransmitter seperti DHEA (dehidroepinandrosteron) dan dopamine atau endofrin. Regulasi system parasimpatis ini akhirnya menimbulkan efek ketenangan (Lestari \& Yuswiyanti, 2015).

Perawat memiliki tanggung 
jawab penuh untuk mengelola stress yang dialami pasien. Teknik IPMR dapat digunakan sebagai salah satu cara untuk mengurangi stress pasien. Teknik IPMR sangat mudah, murah, sederhana dan diimbangi dengan dzikir kepada Allah. Oleh karena itu peneliti ingin meneliti tentang pengaruh Islamic Islamic progressive muscle relaxation $(I P M R)$ terhadap penurunan stress pasien yang diukur melalui kadar kortisol pasien di ruang Azzahra 2 RSI Jemursari Surabaya.

Ruang perawatan Azzahra 2 Rumah Sakit Islam Jemursari adalah ruangan untuk kasus bedah. Kondisi ruangan dikelola sangat kondusif untuk pasien pre operasi dan dimaksudkan untuk mengurangi stress pasien yang akan menjalani operasi.

\section{METODE}

Penelitian ini merupakan penelitian eksperimental dengan pendekatan prepost tes design. Populasi target adalah seluruh pasien pre operasi yang dirawat di Ruang Azzahra 2 mulai bulan September 2017, dengan sampel penelitian sebesar 30 responden didapatkan melalui tehnik simple random sampling. Variabel bebas adalah Islamic progressive muscle relaxation (PMR), sedangkan variable tergantung adalah kadar kortisol. Pengumpulan data kadar kortisol melalui sampel darah pasien. Data dianalisis dengan Wilcoxon sign rank test. Penelitian ini telah dinyatakan laik etik oleh KEPK Unusa pada tanggal 5 September 2017.

\section{HASIL \& PEMBAHASAN}

\section{Hasil}

Tabel 1. Hasil Pengukuran Kadar Kortisol Responden di RSI Jemursari Surabaya, September 2017

\begin{tabular}{|l|c|c|}
\hline \multicolumn{1}{|c|}{ Kortisol } & Pre & Post \\
\hline Mean & 26,51 & 20,10 \\
\hline $\begin{array}{l}\text { p-value (two- } \\
\text { tailed) }\end{array}$ & \multicolumn{2}{|c|}{, 0428} \\
\hline
\end{tabular}

Tabel 1 menunjukkan bahwa rata-rata kadar kortisol sebelum dilakukan tindakan IPMR adalah 26,51. Setelah dilakukan IPMR rata-rata kadar kortisol turun menjadi 20,10. Penurunan kadar kortisol pasien tersebut masih dalam batas normal. Hasil uji statistik menunjukkan adanya penurunan yang signifikan antara kadar kortisol sebelum dan sesudah dilakukan IPMR.

\section{Pembahasan}

Hasil penelitian menunjukkan bahwa ada perbedaan rata-rata kadar kortisol sebelum IPMR dan sesudah IPMR. Pasien pre operasi yang dilakukan IPMR kadar kortisolnya menurun dari kondisi sebelum dilakukan IPMR. Hal itu menggambarkan bahwa pasien pre operasi membutuhkan kesiapan mental yang baik untuk mengendalikan stressor dalam tubuhnya.

Stress adalah hal yang wajar dialami oleh manusia. Kondisi menjelang operasi stress dirasakan semakin tinggi. Skor stress menurun karena pasien dilatih dan dikondisikan relaksasi dengan pendekatan dzikir (Hamdalah dan Istighfar). IPMR dengan pendekatan dzikir akan menghambat jalur umpan balik antara otot dan pikiran, dengan cara mengaktivasi kerja sistem saraf parasimpatis dan memanipulasi hipotalamus melalui 
pemusatan pikiran terhadap Allah SWT, sehingga rangsangan stress terhadap hipotalamus berkurang.

IPMR dapat membantu mengurangi ketegangan otot, menurunkan stress, menurunkan tekanan darah, meningkatkan toleransi terhadap aktivitas sehari-hari, dan meningkatkan imunitas sehingga status fungsional dan kualitas hidup meningkat.

Kortisol adalah hormon yang sangat mudah termodulasi oleh stress. Respon fisiologis tubuh yang paling menonjol terhadap stres adalah peningkatan kortisol (Skosnik, 1999; Ebrecht, 2003). Kortisol merupakan bentuk aktif glukokortikoid dalam peredaran darah. Glukokortikoid merupakan kortikosteroid utama yang dihasilkan oleh korteks adrenal. Sekresi ini dikontrol oleh kelenjar hipofise melalui Adreno Corticotropin Hormon (ACTH). ACTH sendiri dikontrol melalui Corticotropin relising factor (Guyton, 2008). Stres akan memicu peningkatan kadar kortisol dalam darah. Schwertz mengatakan bahwa kortisol akan memblokade reseptor IL 2 dan menekan produksi IL 2 serta IFN $\gamma$ yang merupakan sitokin Th1. Disisi lain Stanius (1997) mengemukakan bahwa dalam jumlah sedikit, kortisol akan memacu produksi sitokin Th2 yaitu IL 4 dan IL 10. Nilai normal kortisol jam 09.00 adalah $170-720 \mathrm{nmol} / \mathrm{l}(6-26$ $\mu \mathrm{g} / 100 \mathrm{ml})$. Kadar kortisol tengah malam 24.00 adalah kurang dari 220 $\mathrm{nmol} / \mathrm{l}(<8 \mu \mathrm{g} / 100 \mathrm{ml})$.

Stress fisik atau stress mental dalam waktu beberapa menit saja dapat meningkatkan sekresi ACTH, sehingga sekresi kortisol juga meningkat dua puluh kali lipat (Guyton, 2012).
Kondisi stres yang dialami seseorang, baik secara fisik maupun emosional akan direspon oleh otak pada hipotalamus. Hubungan otak dengan sistem imun melalui hipothalamo pituitary - adrenal (HPA) axis. Stres fisik maupun psikis diproses oleh hipotalamus sehingga mensekresi CRH. Sinyal dikirim ke hipofise sehingga menstimulasi sekresi ACTH. ACTH ditangkap oleh sel di korteks kelenjar adrenal untuk mensekresi kortisol (Guyton, 2012).

Penelitian lain yang menghasilkan hubungan yang tidak signifikan kemungkinan disebabkan oleh waktu pengambilan darah untuk sampel yang tidak homogen. Namun demikian kadar kortisol penderita tetap mengalami penurunan setelah IPMR artinya stress yang dirasakan pasien berkurang.

\section{SIMPULAN DAN SARAN}

\section{Simpulan}

IPMR menurunkan stress pasien menjelang operasi yang diukur melalui kadar kortisol darah.

\section{Saran}

IPMR dapat dilakukan secara mandiri oleh pasien. Perawat dapat memberikan edukasi kepada pasien menjelang operasi dengan tehnik IPMR. Penelitian lanjutan dapat dikembangkan mengenai hormonhormon yang terstimuli pada kondisi relaksasi.

\section{DAFTAR PUSTAKA}

Chauduri, Arimina., Rau, Manjushree., Saldanha, Daniel., Sarkar, Saljal Kumar., 2015, PMR and Postmenopausal Stress, Journal 
of The Science Society, Vol.2/ Issues 2, p.62-67, Didownload dari http://jscisociety.com on Saturday, May 28, 2016

Chellew, Karin., Evan, Phil., Vives, Joana Fornes., Perez, Gerardo., Banda, Gloria Garcia., 2015, The effect of progressive muscle relaxation on daily cortisol secretion, Stress: The International Journal on the Biology of Stress, Vol.18/issues 5, p. 538-544.

Chrousos, George, 2009, The stress response, http://www.improvemental-health.com/stress-

response.html, diakses tanggal 1 Maret 2012 pukul 14.53 wib

Guyton, Arthur C., dan Hall, John E., 2012, Fisiologi manusia dan mekanisme penyakit, Edisi 3, Jakarta: EGC

Hawari, Dadang, 2009, Psikometri: alat ukur (skala) kesehatan jiwa, Jakarta: Balai Penerbit FKUI

Raustch, Sarah M., Gramling, Sandra

E., Auerbach, Stephan M., 2006, Effects of a single session of large-group meditation and progressive muscle relaxation training on stress reduction, reactivity, and recovery., International Journal of Stress Management, Vol 13(3), Aug 2006, p. 273-290.

Putra, Suhartono Taat., 2011, Psikoneuroimunologi kedokteran, edisi 2, Surabaya: Airlangga University Press

Zahroh C., Khamida, Saleh NR., 2017, Islamic Progressive Muscle Relaxation (PMR) Menurunkan Stres Pasien di Azzahra 2 RSI Jemursari Surabaya, Prosiding
Seminar Nasional Keperawatan Manajemen Perawatan Kesehatan Masyarakat Sebagai Strategi Pencapaian Indikator Keluarga Sehat, p. 85-87 